\title{
O BRINCAR NA ESCOLA: A RELAÇÃO ENTRE O LÚDICO E A MÍDIA NO UNIVERSO INFANTIL ${ }^{1}$
}

GRAD. ISABELLE BORGES SIQUEIRA

Graduada em Educação Física pela Universidade de Brasília (UnB)

Bolsista de Iniciação Científica CNPq/UnB 2009/20 I 0 (Brasília - Distrito Federal - Brasil)

E-mail: ibs.siqueira@gmail.com

\begin{abstract}
DRA. INGRID DITTRICH WIGGERS
Doutora em Educação pela Universidade Federal de Santa Catarina (UFSC)

Pesquisadora do Núcleo Infância, Comunicação, Cultura e Arte (NICA)

Professora do Programa de Pós-graduação em Educação Física da UnB (Braślia - Distrito Federal - Brasil)

E-mail: ingridwiggers@gmail.com
\end{abstract}

\author{
GRAD. VALÉRIA PEREIRA DE SOUZA \\ Graduada em Educação Física pela UnB \\ Bolsista de Iniciação Científica CNPq/UnB 2009/20 I 0 (Brasília - Distrito Federal - Brasil) \\ E-mail: souza.pereira.valeria@gmail.com
}

\section{RESUMO}

A mídia tem se afirmado como um forte componente da realidade na sociedade contemporânea. Há, nesse sentido, um crescente interesse na análise de como as mensagens dos discursos midiáticos estariam presentes no universo infantil. O objetivo do presente estudo foi o de averiguar e analisar a presença da mídia no ambiente escolar, por meio da cultura corporal de movimento infantil. Utilizou-se metodologicamente a observação participante em uma instituição de educação infantil de Brasilia (DF). Como resultado principal, constatou-se que há uma apropriação cultural da mídia pelas crianças em seus momentos lúdicos e em suas relações sociais, refletidas nos jogos simbólicos.

PALAVRAS-CHAVE: Cultura corporal de movimento; infância; jogo simbólico; mídia.

I. Esse estudo integra o projeto de pesquisa "Mídia-educação, infância e educação física" que contou com o apoio financeiro do Programa de Iniciação Científica CNPq/UnB, Edital ProlC-UnB 2009/20 I 0. O referido projeto foi aprovado pelo Comitê de Ética em Pesquisa com Seres Humanos do Instituto de Ciências Humanas da UnB, com base nas Resoluções 196/96 do CNS/MS. Agradecemos o suporte da unidade da Rede "Centro de Desenvolvimento de Estudos do Esporte e do Lazer" (CEDES) da UnB. 
É possível perceber uma forte influência dos veículos midiáticos sobre a formação e estruturação da sociedade contemporânea. A mídia² e suas relações com o ser humano têm tornado-se foco e objetivo de muitos estudos, aspecto comprovado por Azevedo et al. (2007) na pesquisa que revelou um índice crescente de trabalhos com a temática "Comunicação e Educação Física", desde 1997 até 2005.

Batista e Betti (2005) afirmam que o esporte e as práticas corporais são cada vez mais apresentados em noticiários, propagandas, eventos, desenhos, novelas e filmes, o que provoca sua espetacularização. Complementando essa ideia, Araújo e Porpino (2005) acreditam que as atividades esportivas estão sendo utilizadas, principalmente, com a intencionalidade de entretenimento e de consumismo do telespectador. Desse modo, os valores agregados por esses meios de comunicação são incorporados constantemente por jovens e crianças, os quais sofrem interferências significativas nas atitudes e na compreensão das suas relações sociais e pessoais.

Admitindo a importância da mídia e suas influências sobre o processo educativo na atualidade, mostram-se necessários a preparação e esclarecimentos da comunidade de educadores para orientar suas práticas pedagógicas (SAYÃO; MUNIZ, 2005). O uso correto dos recursos midiáticos como uma ação educativa deve ser baseado, fundamentalmente, no estímulo à emancipação e autonomia dos estudantes, provocando um olhar crítico sobre conceitos e valores da realidade. Sob essa concepção, avalia-se a importância da formação para a mídia, tanto dos professores quanto dos alunos para que, dessa maneira, possam se estabilizar como usuários críticos e ativos dos meios de comunicação (BELLONI, 2005). Desse modo, as crianças e os profissionais estarão mais preparados para interagir e criar a partir das informações oferecidas pela mídia.

Percebendo a grande relevância da mídia na formação, informação e educação das crianças, é de responsabilidade da escola e dos professores entenderem e aperfeiçoarem seus conhecimentos na atuação educacional e formativa dos estudantes. Com a intenção de enriquecer os conhecimentos acerca de uma educação para a mídia, é objetivo do presente estudo, averiguar e analisar a presença da mídia em um ambiente escolar, por meio da cultura corporal de movimento infantil. ${ }^{3}$ Buscou-se observar se há, nas brincadeiras e nas relações das crianças entre si e com os

2. No âmbito desse texto, considera-se como mídia os meios de comunicação: televisão, rádio, internet, jornais, revistas, etc.

3. Entende-se como cultura corporal de movimento a exercitação corporal intencionada e sistematizada que constrói as formas simbólicas da cultura na forma de esporte, dança, ginástica etc. (BETTI, 2007). 
professores, a representação e ressignificação de novas possibilidades de movimento e interlocuções baseadas nos conteúdos midiáticos.

Dessa maneira, o trabalho apresenta inicialmente um aporte teórico sobre "o brincar" e sua relação com a cultura midiática infantil. A partir disso, o artigo evidencia resultados encontrados por meio do trabalho de campo e busca desenvolver uma análise qualitativa da cultura corporal de movimento de crianças em um ambiente escolar da rede pública de Brasília.

\section{O JOGO E A CULTURA CORPORAL DE MOVIMENTO}

Autores que se dedicaram a estudar o jogo ou a brincadeira e sua relação com a cultura infantil revelaram, com ênfase na concepção piagetiana, que o ato de jogar e de brincar ocorre desde os primeiros momentos de vida do indivíduo e faz parte do seu desenvolvimento global (RIZZI; HAYDT, 1998). Os jogos e as brincadeiras são mecanismos de aprendizado cognitivo e social, se caracterizando como um momento de descoberta da realidade por parte das crianças de maneira espontânea e expressiva. Nos estudos de Rizzi e Haydt ( 1998), o aspecto lúdico do comportamento humano foi evidenciado de maneira instintiva e até mesmo anterior às influências culturais mais abrangentes do indivíduo. No entanto, o ambiente sócio-cultural e as relações com o meio são fortes mecanismos de interferência nas ações reflexas de ludicidade do ser humano. Segundo Brougère (2000), o jogo é considerado uma representação de aspectos da sociedade, associando a dimensão simbólica a funções específicas do convívio e desenvolvimento humano.

De acordo com Piaget (1964), após um ritual motor ocorrem adaptações, e novos significados são atribuídos pelas crianças aos conteúdos da realidade. Assim, surgem as atividades lúdicas, classificadas como jogo simbólico, as quais são resultados da imitação e reprodução de situações e experiências ocorridas no meio em que a criança está inserida, que transforma e expressa desejos em busca da evocação do prazer.

Ressaltamos, também, que o corpo possui significado, a partir de sua relação e compatibilidade com aspectos da realidade (SANT'ANNA, 1995). Os olhares, as atitudes, os gestos, as feições, as expressões corporais são capazes de apresentar e significar emoções e pensamentos de um indivíduo. Acredita-se que nos momentos de ludicidade é promovida uma estrutura de maior interação entre pessoas e uma maior possibilidade de expressividade corporal. Além dos aspectos anteriormente assinalados, a escola é um dos lugares onde mais se encontra essa estruturação lúdica e, assim, considera-se este ambiente propício, principalmente para as crianças, por proporcionar comportamentos naturais de forma integrada a elementos socioculturais. 
Percebe-se um incremento influenciador dos meios e das próprias tecnologias de comunicação nas práticas recreativas da infância, assim como em suas vivências cotidianas e formativas. No entanto, é preciso compreender que essas representações não são apenas a incorporação de simbolismos sem sentido, mas sim a saída da posição de observador da imagem para ator da atividade lúdica, como resultado de uma impregnação cultural (BROUGÈRE, 2000).

\section{A INFÂNCIA E SUAS RELAÇÕES COM A CULTURA MIDIÁTICA}

Alguns consideram a relação das crianças com os veículos midiáticos algo não proveitoso e até mesmo negativo. Nesse âmbito, a produção teórica da Escola de Frankfurt, chamada de "Indústria Cultural", defende que a mídia provoca uma alienação do sujeito, inibindo sua capacidade de reflexão crítica sobre a realidade (ADORNO; HORKHEIMER, 1985). Corroborando esse paradigma, Postman ( 1999) supõe que essa interação é aproveitada para destruir a individualidade e inocência da criança, provocando a "morte da infância". Quando as crianças têm acesso a mensagens para cuja recepção e interpretação não estariam preparadas, reduz-se a distância entre a infância e a maturidade. Essa concepção de infância pode ser comparada àquela predominante no campo da Educação Física. Segundo Oliveira (2005, p. I 05), "o conceito de infância na área acadêmica de Educação Física está condicionado, sobretudo, ao conceito constituído historicamente na sociedade ancorado nos pressupostos dos sentimentos de paparicação e moralização [...]", que representam uma idealização da infância.

Contrapondo essa perspectiva, é importante destacar as ideias de Sarmento (2005), que critica a visão pejorativa da infância pela sociedade, e seu consequente afastamento do mundo adulto. Para ele, a geração da infância não é apenas uma fase de maturação biológica e desenvolvimento humano intermediário, mas também um objeto de investigação sociológica e uma categoria social de extrema relevância, a qual é continuamente modificada por ações internas e externas de elementos que compõem sua realidade, incluindo os meios de comunicação.

Dessa maneira, exaltando a importância da infância na sociedade e a presença da mídia em sua geração, existem outras análises com visão positiva sobre a mídia. Alguns estudiosos, como Cunha (2007), acreditam que a mídia atua na linguagem e jogos infantis, porém não é um fator condutor e nem determinante em suas explorações. As crianças usam elementos midiáticos em suas brincadeiras com um intuito simbólico e lúdico. Betti (2003) enfoca a televisão e a considera pobre em conteúdo, contudo a define como "semioticamente complexa", considerando-a uma estimuladora do aprendizado cognitivo e psicológico, a partir de sentidos receptores. 
Para esse autor, cada indivíduo interpreta e relaciona as mensagens veiculadas de acordo com suas vivências socioculturais e psíquicas e, por esse fato, não é possível afirmar de maneira geral que a mídia aliena ou desinforma.

Ambas as concepções, todavia, convergem ao considerar os meios de comunicação como parte da cultura contemporânea. É inconteste a apropriação e relação de conteúdos expostos na mídia com as brincadeiras e jogos realizados pelas crianças. Esta consideração pode ser sustentada por Brougère (2000) que afirma, em sua percepção, que a televisão modifica e interfere significativamente na cultura lúdica da criança, a partir do material transmitido.

Nesse contexto, o ambiente escolar se torna importante em dois sentidos: como um espaço onde a criança se apropria e manifesta significados sobre os conteúdos midiáticos absorvidos, por meio de suas relações sociais e verbais com os companheiros (OROZCO, 1997), e como espaço informativo e formativo para uma interação crítica e esclarecedora sobre mensagens advindas da mídia. De acordo com Orozco (1996), vê-se necessária uma intervenção pedagógica da própria escola sobre, especificamente, os conteúdos da televisão, pois é nesse ambiente que há um conflito entre o que é ensinado e aprendido na escola e na TV. Nesse caso, se não ocorrer uma mediação adequada, um possível resultado para a instituição seria uma "perda" de sua responsabilidade educacional. A escola precisa aceitar as realidades de seu tempo e se preparar para enfrentar as dificuldades considerando que "[...] é na escola que o pensamento é fértil e sobrevive." (BITENCOURT et al., 2005, p. 726).

\section{O CAMPO DE PESQUISA E OS PROCEDIMENTOS DE INVESTIGAÇÃO}

Inicialmente, a pesquisa teve um caráter bibliográfico, a partir de artigos publicados ou em periódicos de ampla circulação na área de Educação Física ou em anais de congressos científicos, com ênfase no Congresso Brasileiro das Ciências do Esporte (CONBRACE) de 2005 e de 2007. Além disso, também foram analisados livros considerados referências para o tema proposto, englobando as áreas de Mídia-Educação, Infância e Educação Física.

Adicionalmente, realizamos pesquisa qualitativa, por meio de uma observação participante. Costa e Nascimento (2009) salientam que o comportamento e o ambiente onde um professor está inserido é um campo significativo para se realizar observações. Com isso, pode-se estender esse entendimento para observação de como o professor organiza e utiliza conteúdos, como interage com os alunos e como esses se relacionam entre si. Ainda com base nos referidos autores, afirma-se que um trabalho de campo ocorre mais próximo à realidade se puder 
ser acompanhado no seu cotidiano, pois, dessa maneira, o contexto poderá ser entendido e melhor analisado.

Tendo como base tais orientações, a coleta de dados aconteceu em um jardim de infância da rede pública de ensino no Plano Piloto de Brasília (DF). A instituição foi selecionada considerando-se contatos anteriormente estabelecidos, por meio de atividades realizadas no âmbito de outros projetos acadêmicos. As observações ocorreram durante as atividades da escola, tanto dentro da sala de aula quanto em outros momentos do cotidiano da instituição, tais como a hora do lanche, a chegada e a saída dos alunos à escola. $\bigcirc$ desenvolvimento das visitações se passou em dois períodos. A primeira etapa transcorreu durante um mês. Nessa fase as visitas ocorreram duas vezes por semana, com duração de duas a três horas por dia, sendo em turnos opostos e em turmas distintas, criando, pois, diferentes cenários. Após um período de férias escolares, ocorreu a segunda etapa das observações, que também se estendeu por um mês. Entretanto, nessa outra fase as visitas aconteceram em apenas uma turma, durante três vezes por semana, com duração de duas a três horas cada. Foram escolhidas as turmas mais avançadas do jardim de infância, de acordo com a disponibilidade oferecida pela escola. Portanto, foram aproveitadas experiências com três professoras diferentes e um total de sessenta e três crianças na faixa etária de quatro a seis anos de idade, durante cerca de dois meses.

Complementando a observação do ambiente escolar, formou-se um memorando das observações de campo, cujo objetivo foi o de discriminar os acontecimentos que mereciam destaque, para serem aprofundados e averiguados. Como produto do material empírico coletado, criou-se categorias de codificação para organização e análise dos dados, conforme sugeriram Bogdan e Biklen (1994). Foram encontrados padrões entre os tópicos das categorias e, assim, separados por suas similaridades. A partir disso, a discussão dos dados ocorreu sob a visão teórica formulada preliminarmente, que sustentou as percepções e conclusões dos fatos avaliados.

\section{PERCEPÇÕES DA MÍDIA NO UNIVERSO INFANTIL}

Em um primeiro plano da observação de campo, destacaram-se elementos mais imediatos e perceptíveis no cotidiano das crianças. Roupas, mochilas, bonecas, adesivos e figurinhas identificavam a reprodução de assuntos midiáticos, materiais concretos voltados para um consumismo infantil. As meninas mostravam suas sandálias da Barbie e suas mochilas das princesas da Disney ou da personagem "Moranguinho", assim como suas bonecas "Polly". Os meninos, casacos do filme animado "Carros", camisas do "Batman", bonés do "Ben I0", pulseiras do "Homem-Aranha" e bonecos da "Era do Gelo". 
Para se compreender o fenômeno do consumismo, cabe discorrer sobre a publicidade. Essa é um fenômeno social complexo que pode ser compreendido no cotidiano e entendido como mecanismo de comunicação persuasivo, cujo objetivo é voltado ao mercado e aos parâmetros capitalistas (PIEDRAS, 2007). Com efeito, "[...] os brinquedos mais vendidos são, na maior parte dos casos, aqueles que são objetos de uma campanha publicitária televisiva" (BROUGÈRE, 2000, p.57). O consumidor interpreta, ressignifica e assimila as informações da publicidade, reestruturando o modo como querem utilizá-las. $\bigcirc$ mesmo processo acontece com a criança que, hoje, não é mais apenas considerada pelo mercado como filha de cliente, tendo sido elevada ao status de cliente, pois está exposta a inúmeros anúncios publicitários dedicados exclusivamente a ela. Essa manifestação pode ser vislumbrada no constante desejo infantil por mercadorias. De acordo com Souza et al. (2000, p. 442), o mundo do consumo promete oferecer prazeres absolutos, e ao mesmo tempo se apresenta como a "[...] condição de inserção em um mundo que promete a satisfação de desejos que ele mesmo produziu".

A propaganda voltada para o público infantil pode ser vista apenas como um instrumento de manipulação e exploração comercial. Por outro lado, a relação da criança com o objeto e seu sentimento de posse sobre este, remete ao desenvolvimento de habilidades de negociação, escolhas e percepção sobre a utilização e compra do produto desejado, desencadeando a criação de esquemas sociais que auxiliam no processo de socialização da criança (BROUGÈRE, 2000). Portanto, não se deveria considerar, sob uma ótica unilateral, nocivo o interesse das crianças por objetos que são associados aos conteúdos presenciados no contato com a mídia. $\bigcirc$ fato não é que elas se tornam alienadas e consumistas, mas sim que reproduzem e incorporam um contexto que se integra à sua realidade cultural e social.

Em outro âmbito, a mídia também pôde ser observada na cultura corporal de movimento e em vários momentos lúdicos. A dança da Xuxa, ${ }^{4}$ por exemplo, era coordenada por uma das crianças e, no momento certo, todas deviam imitar estátuas. As meninas se transformavam em manequins e os meninos em super-heróis. As formações das estátuas refletiam a apropriação e interpretações das crianças sobre conteúdos culturais que as cercam. Embora essa brincadeira não reproduza somente as mensagens midiáticas, não podemos desconsiderar em sua análise que o mundo da mídia e o seu reflexo na sociedade revelam que as manequins são inspiradoras por possuírem corpos "perfeitos" e que os super-heróis são os seres

4. A Xuxa pode ser considerada uma personagem mais antiga que demonstra resistir como parte do imaginário de crianças brasileiras, entre o apelo de muitas outras oferecidas a cada ano pela mídia para preencher o universo da cultura infantil. 
fortes, imbatíveis e capazes de acabar com o mal. Não é de se surpreender que, durante suas brincadeiras, as crianças expressem seus desejos de tornarem os seus corpos modelos dos padrões que thes são apresentados.

Diversos estudos já evidenciaram que figuras midiáticas ampliam suas funções quando são aproveitadas pela indústria do consumo para a divulgação de outros produtos a serem ofertados pelo mercado ao consumidor. "Mas o fenômeno mais comum é que se tornam modelos de comportamento e modos de ser para o seu público alvo: todos assistem, imitam e se vestem como os seus ídolos." (SOUZA, 2000, p. 445). Em outro estudo foi evidenciado que crianças tendem a reproduzir, em desenhos de figuras humanas, as formas corporais propagadas pela mídia, demonstrando as influências sociais e culturais mais marcantes por meio das quais elas forjariam a construção de sua cultura corporal. Entretanto, destacou a autora que "[...] de um ponto de vista histórico, os desenhos das crianças não estariam aprisionados ao determinismo social. Eles dariam às crianças, sendo uma linguagem, a possibilidade de (re)significar, (re)inventar e virtualmente transgredir a própria realidade na qual se inserem" (WIGGERS, 2005, p. 75).

A mídia como ferramenta de interatividade das crianças também foi identificada no trabalho de Batista e Betti (2005). Esses autores realizaram um estudo utilizando o desenho animado como recurso de intervenção na disciplina Educação Física, pois, ao avaliar pesquisas anteriores e experiências profissionais, consideraram o desenho como o gênero televisivo preferido das crianças. Entre diversas figuras, o "Ben 10" foi o que mais se destacou no processo de apropriação da mídia para formação do universo simbólico das crianças. É muito interessante ver como um personagem, capaz de se transformar em diversas criaturas, encanta tanto meninos quanto meninas. Segundo Brougère (2000), um herói de um desenho animado é o bastante para as crianças ajustarem comportamentos e entrarem de forma igualitária em uma brincadeira. $\bigcirc$ desenho se mostrou como um instrumento de integração entre os alunos, pois para iniciar uma conversa ou brincadeira bastava "tornar-se" um ser muito forte, chamado o "Besta", que, segundo o entendimento das crianças, é um sapo sem olhos, mas capaz de enxergar.

No âmbito de suas brincadeiras, as crianças, ao manusear a massinha de modelar, também faziam bonecos do "Ben 10". No momento lúdico, os bonecos lutavam entre si e reproduziam o cenário do desenho. Uma menina pegou um tigre de plástico do filme infantil "A Era do Gelo" e "atacou", destruindo o boneco de massinha do "Ben 10" de um de seus colegas. A indignação do garoto foi expressa com a frase: "- A briga era só de mentirinha! Por que você estragou o meu boneco?".

Dentro desse mundo da imaginação, dois garotos sugeriram brincar de rodar. A brincadeira consistia em girar o colega, "cortar" sua cabeça e jogá-lo 
contra a parede, porém afirmando categoricamente que nada daquilo machucaria de verdade. Para muitos adultos, principalmente professores e pais, essas cenas seriam representações da violência presente nos atuais programas midiáticos. No entanto, para os alunos que estavam na brincadeira, tudo parecia ser divertido, sem qualquer violência real ou agressão física. Houve muitos momentos em que o lúdico se manifestava em cenas de lutas e troca de tiros, contudo eram jogos simbólicos, baseados em contextos e informações de imagens e da cultura midiática que as crianças compartilham. $\bigcirc$ uso da expressão "é de mentirinha" é a confirmação de como essas brincadeiras fazem parte da imaginação e do mundo de "faz-de-conta" que as crianças criam para sustentar suas experiências lúdicas, além de ser um aspecto que deve ser levado em conta para caracterizar se a vivência é uma brincadeira ou não.

Cunha (2007) revelou, em seu estudo, que os jogos de luta e de guerra também foram observados em seu campo de pesquisa. Constatou a autora a preocupação das crianças em não se machucarem "de verdade", mantendo em pauta um universo simbólico próprio, sem, no entanto, passar pelas consequências reais da violência. Além disso, verificou que mesmo crianças que passavam horas jogando games (videogames) violentos, não demonstravam qualquer comportamento diferenciado e agressivo nas brincadeiras "de baixo do prédio" onde viviam.

Brougère (2000), em suas interpretações da relação brinquedo/cultura, já afirmava que a criança se apropria e adapta conteúdos do seu mundo exterior às suas próprias atividades de interesse, como o brincar. Com base nessa mesma concepção, independente da mídia, a violência faz parte da realidade humana e, consequentemente, da cultura infantil, e é por meio da brincadeira que a criança se confronta simbolicamente com a violência. Segundo o autor, o jogo de guerra é uma brincadeira construída culturalmente e serve como um mecanismo de fuga da rotina das crianças, porém é uma busca da aventura e de expressão de uma agressividade controlada e socialmente aceita, considerando que é possível manipular cenas simbólicas de violência sem agressividade.

Em um momento livre no parquinho, dois garotos faziam das suas mãos formatos de armas e disparavam "tiros" um contra o outro. "[...] A criança, com ajuda do seu corpo, desempenha um papel. O brinquedo é um prolongamento do corpo, prolongamento este que é fácil de se fazer: dois dedos são suficientes para imitar um revólver" (BROUGÈRE, 2000, p.82). A violência na experiência infantil pode ser reinterpretada como a utilização do corpo como objeto de ludicidade, conferindo à cultura corporal de movimento um caráter simbólico. 
Complementarmente, percebeu-se a simbologia em diversas brincadeiras dos alunos. ${ }^{5}$ Nas cenas observadas, uma criança montada em cima de outra agachada se transformava em um peão de touro; massinhas modeladas representavam "comidinhas" apetitosas; um caixote se transformava em "super-carro"; a calculadora em um lindo celular, e vários heróis e personagens de desenhos animados se manifestavam como resultado do imaginário das crianças. Para Piaget (2007), o jogo simbólico se caracteriza pela utilização de um objeto na incorporação do "faz-de-conta" e adequação do mundo exterior aos desejos da criança e esquemas ausentes na realidade.

A imitação, de acordo com Piaget ( 1964 ), também é um conteúdo importante das funções simbólicas. Uma aluna dançava, segundo ela simulando o quadro "Se vira nos 30" do programa "Domingão do Faustão", enquanto outra a imitava. Em situação apresentada por uma das crianças, o jogo Gogo's tornou-se brincadeira preferida da turma, na qual o objetivo era lançar seu bonequinho de plástico para derrubar o do adversário. Não obstante, a maioria das brincadeiras, inclusive as últimas relatadas, era repetida diversas vezes e era constante no cotidiano dos alunos. Nesse cenário, consideram-se as percepções de Freud, de que o jogo é identificado como um campo de repetições, cujo comportamento lúdico é uma compulsão de situações repetidas (BROUGÈRE, 1998).

De forma geral, a televisão revelou-se o meio de comunicação mais presente nas expressões diárias observadas entre os alunos. Na sociedade contemporânea, segundo Costa e Betti (2006), a televisão é um integrante enraizado do ambiente escolar e se aplica como a forma mais poderosa da mídia. Os programas de entretenimento televisivo, ressalte-se ainda, podem ser encarados como os principais produtos que visam promover o consumo.

Para Girardello (2005), a função da televisão é uma variável de acordo com a vida de cada criança e da qualidade de seu cotidiano. Como estrutura do cotidiano, considera-se os seguintes fatores como mais importantes: a extensão do tempo que a criança passa assistindo TV, o tipo de mediação do adulto e o conteúdo da programação. De acordo com a pesquisadora, não é plausível considerar que a mídia é alienante, pois o modo como é recebida por cada usuário pode variar. Por conseguinte, deve ser assumida como papel da escola, a mediação e a intervenção adulta adequada diante da mídia na vida das crianças.

5. De acordo com Piaget (2007), as crianças entre quatro e seis anos, idade que corresponde a das crianças observadas por esse estudo, experimentam uma fase de desenvolvimento denominada por ele de fase pré-operatória, na qual se evidencia o jogo simbólico. 
Como vimos, a assimilação dos programas midiáticos e do mundo exterior por parte das crianças se dá, por um lado, por imitação e, por outro, considerando suas próprias interpretações. Seria impossível isolá-las dos assuntos referentes à mídia, o que fez Munarim (2007) concluir: a infância é construída com a ajuda da mídia. Para mais disso, a mídia colabora significativamente na configuração da cultura corporal infantil, segundo Wiggers (2008). Como vimos também, a construção cultural das crianças ocorre em grande parte na escola e, dentro desse quadro, aceitando a mídia na formação e contexto infantil, constata-se ser necessário prepará-las para receber adequadamente as mensagens dos meios de comunicação. Como suporte para essa apropriação há, atualmente, diversas propostas para incorporar a mídia no âmbito educacional, como por exemplo, as desenvolvidas por Belloni (2005), Pires (2003), Betti (2003), entre outras, que defendem que a criança deve ser preparada na educação escolar para atuar na sociedade com competências críticas, ativas e reflexivas sobre as mensagens midiáticas recebidas.

\section{CONSIDERAÇÕES FINAIS}

Em um primeiro plano, constatamos que as mensagens midiáticas são exploradas no universo infantil e são refletidas na forma de consumismo, evidenciado nos trajes, objetos pessoais, preferências e comportamento das crianças. Outra observação nos levou a concluir que as mensagens amplamente veiculadas pela mídia, incluindo aquelas que enfatizam a violência, ocupam um lugar importante, tornando-se conteúdo de brincadeiras e jogos simbólicos vivenciados por crianças. A televisão revelou-se, ainda, como o veículo comunicacional mais usufruído pelas crianças pesquisadas, tendo como destaque os desenhos animados, os quais apareceram como o tipo de programação mais inspiradora no contexto de interação dos alunos. Pode-se concluir, nesse sentido, que os conteúdos midiáticos exercem uma função socializadora entre as crianças, caracterizando-se como referências comuns na criação de suas experiências lúdicas.

Não surpreende que o comportamento e as brincadeiras das crianças reflitam as mensagens midiáticas, mas a percepção de que a escola necessita atuar na perspectiva da mídia-educação coloca-nos um desafio. Considerando os resultados da pesquisa e a relevância dos meios de comunicação na realidade formativa das crianças, faz-se necessária uma expansão de estudos sobre o uso da mídia na educação escolar e a aplicação de propostas para o desenvolvimento de um olhar crítico das crianças sobre a mídia. 
Playing at school: relation between leisure and media in children's universe ABSTRACT: Media has established itself as a strong component of the reality in contemporary society. In this sense, there is a growing interest in the analysis of how media issues influences children's universe. From this perspective, this study aims to investigate and analyze the presence of the media at school by observing the body behavior in children's movements. An interactive observation at a public children school in Brasilia was methodologically used. As a result, it was found that there is a cultural interaction of media by children in their leisure moments and in their social relationship, which is reflected in symbolic games.

KEYWORDS: Culture of body movement; childhood; symbolic games; media.

El juego en la escuela: la relación entre el lúdico y la midea en el universo infantil RESUMEN: La midea se ha establecido como un fuerte componente de la realidad de la sociedad contemporánea. Hay, en consecuencia, un creciente interés en analizar como los medios de comunicación son temas que influyen en el universo infantil. Sob este punto de vista, el objetivo de este estudio es investigar y analizar la presencia mediática en el entorno escolar a través de la cultura corporal del movimiento en los niños. Ocurrió en la metodologia una observación participante en uma escuela pública de educación infantil de Brasilia-DF. Como resultado, se constató que existe una apropiación de la midea por los niños en sus momentos lúdicos y en sus relaciones sociales, que se refleja en los juegos simbólicos.

PALABRAS CLAVE: Cultura corporal del movimiento; infancia; juego simbólico, midea.

\section{REFERÊNCIAS}

ADORNO, T.; HORKHEIMER, M. Dialética do esclarecimento: fragmentos filosóficos. Rio de Janeiro: Zahar, 1985.

ARAÚJO, A.; PORPINO, K. O esporte espetáculo e o fenômeno estética: elementos para discutir Educação Física. In: CONGRESSO BRASILEIRO DE CIÊNCIAS DO ESPORTE, I4., 2005, Porto Alegre. Anais... Porto Alegre: CBCE, 2005, v. I, p. 820-830.

AZEVEDO, V. et al. A produção do GTT Educação Física, Comunicação e Mídia/CBCE Período 1997-2005: estudo de uma centena de textos. In: CONGRESSO BRASILEIRO DE CIÊNCIAS DO ESPORTE, 15., 2007, Recife. Anais... Recife: CBCE, 2007, v. I, p. I-6.

BATISTA, S.; BETTI, M. A televisão e o ensino da Educação Física escolar: uma proposta de intervenção. Revista Brasileira de Ciências do Esporte, Campinas, v. 26, n. 2, p. I35- 148 , jan. 2005.

BELLONI, M. L. O que é mídia-educação? 2. ed. Campinas: Autores Associados, 2005. 
BETTI, M. Imagem e ação: a televisão e a Educação Física escolar. In: e mídia: novos olhares, outras práticas. São Paulo: Hucitec, 2003. p. 91-137. . Educação Física

Das "imagens em ação" às "imagens em avalia-ação": uma pesquisa-ação sobre o uso de matérias televisivas em programas de Educação Física escolar. CONGRESSO BRASILEIRO DE CIÊNCIAS DO ESPORTE, I 5., 2007, Recife. Anais... Recife: CBCE, 2007, V. I, p. I-10.

BITENCOURT, F. et al. Educação Física e meios de comunicação: relações dialógicas para a prática escolar - um relato de experiência no CEFETSC/SJ. CONGRESSO BRASILEIRO DE CIÊNCIAS DO ESPORTE, I4., 2005, Porto Alegre. Anais... Porto Alegre: CBCE, 2005, v. I, p. 719-727.

BOGDAN, R.; BIKLEN, S. Investigação qualitativa em educação: uma introdução à teoria e aos métodos. Porto: Porto, 1994.

BROUGÈRE, G. Jogo e educação. Porto Alegre: Artes Médicas, 1998. Brinquedo e cultura. 3. ed. São Paulo: Cortez, 2000.

COSTA, A.; BETTI, M. Mídias e Jogos: do virtual para uma experiência corporal educativa. Revista Brasileira de Ciências do Esporte, Campinas, v. 27, n. 2, p. I65-178, jan. 2006.

COSTA, L. C.; NASCIMENTO, J. O "bom" professor de Educação Física: possibilidade para a competência profissional. Revista da Educação Física/UEM, Maringá, v. 20, n. I, p. 17-24, $1^{\circ}$ trim. 2009.

CUNHA, C. Mídia e criança: a permanência dos jogos tradicionais. In: CONGRESSO BRASILEIRO DE CIÊNCIAS DO ESPORTE, I5., 2007, Recife. Anais... Recife: CBCE, 2007, v. I, p. I-8.

GIRARDELLO, G. Produção cultural infantil diante da tela: da TV à internet. In: REUNIÃO ANUAL DA ANPED, 28., 2005, Caxambu. Anais... Rio de Janeiro: ANPED, 2005. v. I, p. $1-16$.

MUNARIM, I. Televisão e brincadeira: as mediações e o imaginário na cultura de movimento das crianças. CONGRESSO BRASILEIRO DE CIÊNCIAS DO ESPORTE, I 5., 2007, Recife. Anais... Recife: CBCE, 2007, v. I, p. I-9.

OLIVEIRA, N. R. C. de O. Concepção de infância na educação física brasileira: primeiras aproximações. Revista Brasileira de Ciências do Esporte, Campinas, v. 26, n. 3, p. 95- I09, maio 2005.

OROZCO, G. Televisión y audiencias: um enfoque cualitativo. Madrid: Ediciones de la Torre, 1996. p. 159-178.

Professores e meios de comunicação: desafios, esteriótipos. Comunicação e Educação, São Paulo, v. 10, p. 57-68, set./dez. 1997. 
PIAGET, J. A formação do símbolo na criança. Tradução de Álvaro Cabral e Christiano Monteiro Oiticica. 3. ed. Rio de Janeiro: Livros Técnicos e Científicos, 1964.

Epistemologia genética. 3. ed. São Paulo: Martins Fontes, 2007. p. 16-24.

PIEDRAS, E. A publicidade a partir do cotidiano: explorando uma estratégia pluri-metodológica. ENCONTRO DA COMPÓS, 16., 2007, Curitiba. Anais... Curitiba: COMPÓS, 2007. v. I , p. I - I 8.

PIRES, G. de L. Cultura esportiva e mídia: abordagem crítico-emancipatória no ensino de graduação em Educação Física. In: BETTI, M. Educação física e mídia: novos olhares, outras práticas. São Paulo: Hucitec, 2003. p. 19-44.

POSTMAN, N. O desaparecimento da infância. Rio de Janeiro: Graphia, 1999.

RIZZI, L.; HAYDT, R. C. Atividades lúdicas na educação da criança. São Paulo: Ática, 1998.

SANT'ANNA, D. B. (Org.). Políticas do corpo. São Paulo: Estação Liberdade, 1995.

SARMENTO, J. Gerações e alteridade interrogação a partir da sociologia da infância. Revista Educação e Sociedade, Campinas, v. 26, n. 91, p. 36I-368, maio/ago. 2005.

SAYÃO, M.; MUNIZ, N. A mídia em um planejamento para a Educação Física escolar. CONGRESSO BRASILEIRO DE CIÊNCIAS DO ESPORTE, 14., 2005, Porto Alegre. Anais... Porto Alegre: CBCE, 2005, v. I, p. 6I0-6I4.

SOUZA, S. J. et al. A infância na cultura do consumo. CONGRESSO INTERNACIONAL "OS MUNDOS SOCIAIS E CULTURAIS DA INFÂNCIA", 2000, Braga. Anais... Braga: Instituto de Estudos da Criança Universidade do Minho, 2000, v. 3, p. 440-447.

WIGGERS, I. D. Cultura corporal infantil: mediações da escola, da mídia e da arte. Revista Brasileira de Ciências do Esporte, Campinas, v. 26, n. 3, p. 59-78, maio 2005.

WIGGERS, I. D. Infância e mídia: crianças desenham novas corporeidades? In: FANTIN,M; GIRARDELLO, G. (Org.). Liga, roda, clica: estudos em mídia, cultura e infância. Campinas: Papirus, 2008. v. I. p. 75-98.

Recebido: 30 set. 2010

Aprovado: 15 jun. 2011

Endereço para correspondência: Ingrid Dittrich Wiggers

Universidade de Brasília Faculdade de Educação Física Campus Darcy Ribeiro

Gleba B

Brasília - DF - Brasil

CEP 70.919-970 